\title{
Degradation of Anionic Dye using Fe /Tio2 Composite by Photocatalysis
}

\author{
B.Saritha, M.P. Chockalingam, Aswathy.M
}

\begin{abstract}
Dyeing industry discharges large amount of colored wastewater into water bodies without proper treatment. There are various methods to treat wastewater, but recently Photocatalytic treatment has been proven effective. So an effective Iron /Titanium Dioxide (Fe/TiO2) photocatalytic composite has been synthesized by sol-gel method. The synthesized Fe /TiO2 composite was characterized by scanning electron microscope (SEM), X-ray diffraction (XRD), Energy Dispersive Spectroscopy (EDAX). The photocatalytic degradation study of Fe/TiO2 composite under UV light was studied using the aqueous solution of anionic dye Congo Red. The effect of various parameters such as catalyst loading, $p H$ and initial concentration of the dye on degradation has been investigated. The maximum degradation of Congo Red dye concentration in aqueous medium was obtained at $\mathrm{pH}=5$ and $200 \mathrm{mg} / \mathrm{l}$ of $\mathrm{Fe} / \mathrm{TiO} 2$ composite for $10 \mathrm{mg} / \mathrm{l}$ concentration of Congo Red dye. Finally, the results prove that photodegradation of Congo Red dye in aqueous solution using composite was very effective under $U V$ irradiation
\end{abstract}

Keywords : Photocatalytic degradation, Congo Red dye, Sol-gel, Fe/TiO2 composite, $U V$ irradiation

\section{INTRODUCTION}

Coloring enterprises releases immense measure of shaded wastewater which are very lethal that contaminates nature. Throughout the most recent couple of decades enormous scale use of synthetic compounds in different human exercises has become extremely quick, especially in a nation like India which needs to go for fast industrialization so as to continue over developing huge issue of populace. The real wellspring of water contamination is residential waste from urban and rustic regions, and mechanical squanders which are released into characteristic water bodies.

Ground water is the biggest wellspring of crisp water in creating nations and it is likewise exposed to such peril (2).Therefore corruption of the colors in modern wastewaters has created significant consideration because of their enormous volume of generation, moderate biodegradation, low decoloration and high toxicity(3-6).Various physico-substance treatment strategies are broadly utilized for treatment of these waste waters. Among all treatment strategies, photocatalytic degrdation is a promising method, for expulsion of different poisonous synthetic compounds found in wastewater. Heterogeneous photocatalytic oxidation is a powerful strategy to expel low groupings of natural contaminants (7).

Shading endeavors discharges huge proportion of concealed wastewater which are deadly that taints nature. All through the latest couple of decades gigantic scale utilization of manufactured mixes in various human activities has turned out to be amazingly brisk, particularly in a country like India

which needs to go for quick industrialization in order to proceed over creating tremendous issue of people. The present case of current development changes the typical movement of materials and brings novel engineered substances into nature (1). The genuine wellspring of water pollution is private waste from urban and natural locales, and mechanical wastes which are discharged into trademark water bodies.

Ground water is the greatest wellspring of fresh water in making countries and it is moreover presented to such risk (2).Therefore defilement of the hues in current wastewaters has made critical thought in view of their colossal volume of age, moderate biodegradation, low decoloration and high toxicity(3-6).Various physico-substance treatment methodologies are comprehensively used for treatment of these waste waters. Among all treatment procedures, photocatalytic degrdation is a promising strategy, for removal of various noxious manufactured mixes found in wastewater. Heterogeneous photocatalytic oxidation is a ground-breaking methodology to remove low groupings of characteristic contaminants (7).

\section{EXPERIMENTAL STUDY}

\section{A. Materials}

All synthetic concoctions were of systematic evaluation reagents moving along without any more cleaning and obtained from Merck Company. Titanium Isopropoxide, Ferric Nitrate $[\mathrm{Fe}(\mathrm{NO} \neg 3) \neg .3 \neg 9 \mathrm{H} \neg 2 \neg \mathrm{O}]$ were utilized as got and obtained from Merck, India and were utilized moving forward without any more purging. Congo Red color was acquired from material industry. The atomic structure of Congo Red color is given in Fig. 1. Refined water was utilized for readiness of color arrangements. The $\mathrm{pH}$ of the arrangements were balanced with $\mathrm{HCl} / \mathrm{NaOH}$. [20], [ 22], [24]

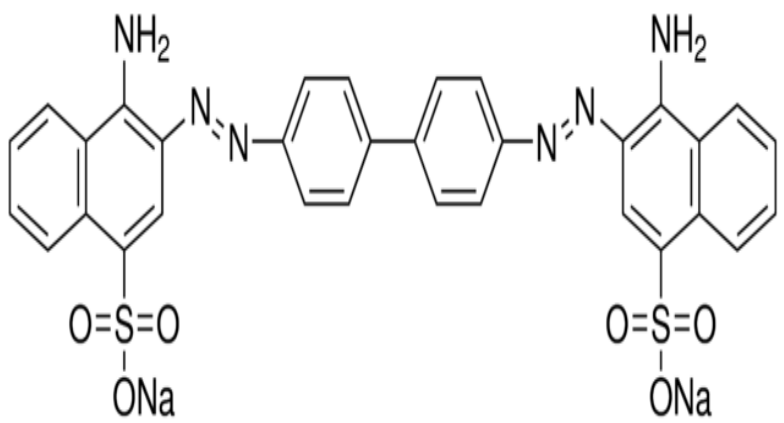

Figure 1: Structure of Congo Red Dye 


\section{B. Photocatalytic Reactor}

The photocatalytic experiments were carried out in batch immersion type reactor. The reactor consists of a long [13], [15] , [ 17]tube made of quartz which was placed inside the glass reactor fitted with standard joint. The reactor consists of $8 \mathrm{~W}$ low pressure mercury vapor lamp which was placed inside the quartz tube.

\section{Synthesis of $\mathrm{Fe} / \mathrm{TiO} 2$ composite}

Mix few $\mathrm{ml}$ of Titanium Isopropoxide with 2-propanol and distilled water. Then add Fe(NO3)3 9H2O solution to it. Mix it well using magnetic stirrer for $4 \mathrm{hrs}$. Keep this mixture in oven at $100^{\circ} \mathrm{C}$ for $10 \mathrm{hrs}$. Then cool to room temperature. Then heat the mixture at $450^{\circ} \mathrm{C}$ for $5 \mathrm{hrs}$ in Muffle Furnace to obtain $\mathrm{Fe} / \mathrm{TiO} 2$ photocatalytic composite.

\section{Photocatalytic Degradation of the Dye under UV Irradiation}

Investigations were done under UV light. To $200 \mathrm{ml}$ of color arrangement, a specific measure of impetus was added and suspension was exposed to UV light illumination. The watery suspension was blended all through the examination. A little amount of the example was taken after certain time interim, $\mathrm{Fe} / \mathrm{TiO} 2$ composite were isolated utilizing rotator and the debasement rates were determined from assimilation estimations of Congo Red color focus estimated utilizing UV-Visible spectrophotometer

\section{RESULTS AND DISCUSSIONS}

\section{Characterization of $\mathrm{Fe} / \mathrm{TiO} 2$ composite}

\section{A . Surface morphological studies}

The SEM images of $\mathrm{Fe} / \mathrm{TiO} 2$ composite depicts the surface features which has been shown in Fig. 2. (a) and (b). Here the particles are agglomerated and are truely spherical in shape. Boundaries of particles are clearly shown in the SEM study of $\mathrm{Fe} / \mathrm{TiO} 2$ composite. The surface texture and porosity nature of the composite is observed, this defines $\mathrm{Fe} / \mathrm{TiO} 2$ composite as nanoparticles of few nanometer size in the form of nano clusters.

\section{B. XRD measurement}

The XRD results for $\mathrm{Fe} / \mathrm{TiO}_{2}$ composite (Fig.3.) have peaks at $2 \Theta$ values of $25.52^{\circ}, 38.05^{\circ}, 48.16^{\circ}, 54.31^{\circ}$, $62.85^{\circ}, 70.42^{\circ}$ and $75.35^{\circ}$ can be assigned to the diffractions of (101), (112), (200), (105), (204), and (215) which indicates the formation of anatase phase of $\mathrm{TiO}_{2}$.

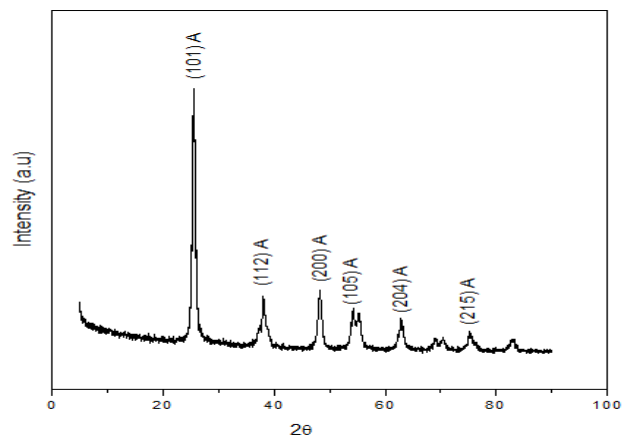

Figure 1: XRD pattern of $\mathrm{Fe} / \mathrm{TiO}_{2}$ composite

\section{EDAX Spectrum}

The EDAX spectrum for $\mathrm{Fe} / \mathrm{TiO} 2$ composite shows different peaks which clearly depicts the presence of $\mathrm{Ti}, \mathrm{Fe}$ and O. The EDAX (Energy Dispersive Spectroscopy) analysis of $\mathrm{Fe} / \mathrm{TiO}_{2}$ composite has been shown in Fig. 2. [14],[16], [18]

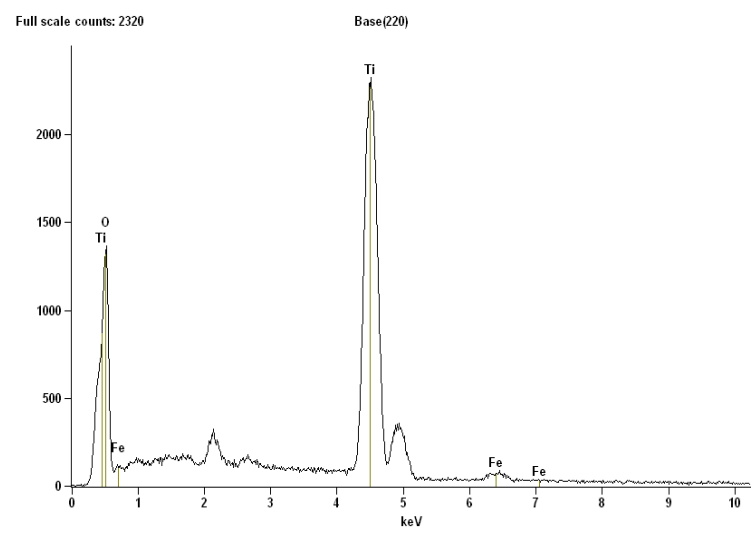

Figure 2: EDAX spectrum of $\mathrm{Fe} / \mathrm{TiO}_{2}$ composite

\section{Photocatalytic Batch Study}

\section{A . Effect of catalyst loading}

Bunch photocatalytic examinations were done utilizing different measurements of $\mathrm{Fe} / \mathrm{TiO} 2$ composite (50 to $300 \mathrm{mg} / \mathrm{l}$ ) with consistent convergence of $10 \mathrm{mg} / \mathrm{l}$ of Congo Red color (Fig.5). It was seen that as $\mathrm{Fe} / \mathrm{TiO} 2$ composite portion expanded, the rate debasement of color fixation expanded. Over $200 \mathrm{mg} / \mathrm{l}$ of $\mathrm{Fe} / \mathrm{TiO} 2$ composite portion, there is no critical increment in the debasement of color. Along these lines, $200 \mathrm{mg} / \mathrm{l}$ of $\mathrm{Fe} / \mathrm{TiO} 2$ composite has been considered as an upgraded portion for debasement of Congo Red color. The expansion in corruption rate with increment in the impetus stacking is because of increment in all out dynamic surface zone for example accessibility of increasingly dynamic destinations on impetus surface. However, higher portion of impetus brings about increment in turbidity of the suspension which diminishes the infiltration of UV light and consequently photoactivated volume of suspension. Accordingly it very well may be reasoned that higher portion of impetus may not be helpful both in perspective on accumulation just as decreased illumination field because of light dissipating. [20],[22], [24]

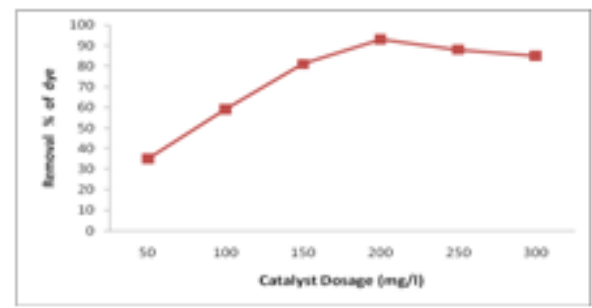


Figure. 3: Study of effect of catalyst dosage

\section{B . Effect of pH}

Material coloring wastewater is released at various $\mathrm{pH}$; along these lines it is critical to consider the job of $\mathrm{pH}$ on corruption of color. So as to contemplate the impact of $\mathrm{pH}$, tests were done at different $\mathrm{pH}$ esteems ( 2 to 8 ) at steady color fixation $(10 \mathrm{mg} / \mathrm{l})$ with $\mathrm{Fe} / \mathrm{TiO} 2$ composite $(100 \mathrm{mg} / \mathrm{l})$. It was seen that the debasement effectiveness increments with increment in $\mathrm{pH}$ and most extreme corruption of $85 \%$ for $\mathrm{Fe} / \mathrm{TiO} 2$ composite was seen at $\mathrm{pH} 5$ (Fig. 6). When changing upto $\mathrm{pH} 8$ there is no critical increment in corruption. This demonstrates the shading expulsion proficiency of photocatalyst relies upon $\mathrm{pH}$. [26],[28],[30]

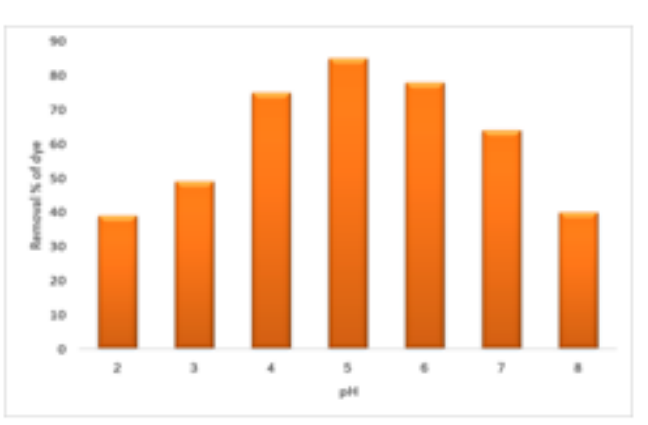

Figure 4: Study of effect of $p$

\section{Effect of initial dye concentration}

The effect of starting centralization of shading course of action has been investigated on the photocatalytic corruption at perfect $\mathrm{pH}$ (5) and driving force divide (Fe/TiO2 composite $=200 \mathrm{mg} / \mathrm{l}$ ). The shading center was contrasted from 50 to $150 \mathrm{mg} / \mathrm{l}$. The clarification for this lead may be a result of the extension in the level of adsorption on the reactant surface which lessens the synergist activity. It has been seen from the Fig.7. The corruption decreases with augmentation in shading obsession with the impulse. At high shading center a great deal of UV light may be devoured by the shading molecule rather than the impulse and this may in like manner lessen the synergist viability. [7],[9] ,[11]

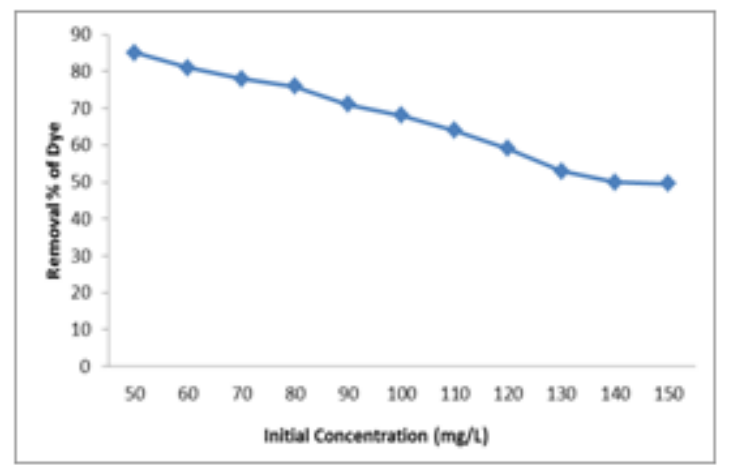

Figure. 5: Study of effect of initial dye concentration

\section{CONCLUSION}

In this research work, the $\mathrm{Fe} / \mathrm{TiO} 2$ composite has been synthesized successfully by sol-gel method and the

characterizations clearly depicted the anatase phase of the synthesized $\mathrm{Fe} / \mathrm{TiO} 2$ composite. The $\mathrm{Fe} / \mathrm{TiO} 2$ composite dosage, $\mathrm{pH}$ of the solution and dye concentration plays a significant role in the photodegradation activity. Thus composite dosage $=200 \mathrm{mg} / \mathrm{l}$ and $\mathrm{pH}=5$ was found to be the optimal $\mathrm{pH}$ for $10 \mathrm{mg} / \mathrm{l}$ concentration of Congo Red dye under the photocatalytic batch study. Thus Congo Red dye has been effectively degraded to more extent with $\mathrm{Fe} / \mathrm{TiO} 2$ composite along with UV light.

\section{REFERENCES}

1. Iyappan L., Dayakar P., Identification of landslide prone zone for coonoortalukusing spatial technology, International Journal of Applied Engineering Research,V-9,I-22,PP-5724-5732,Y-2014.

2. Kumar J., Sathish Kumar K., Dayakar P.,Effect of microsilica on high strength concrete, International Journal of Applied Engineering Research,V-9,I-22,PP-5427-5432,Y-2014.

3. Dayakar P., Vijay Ruthrapathi G., Prakesh J., Management of bio-medical waste, International Journal of Applied Engineering Research,V-9,I-22,PP-5518-5526,Y-2014.

4. Swaminathan N., Dayakar P., Resource optimization in construction project, International Journal of Applied Engineering Research,V-9,I-22,PP-5546-5551,Y-2014.

5. Venkat Raman K., Dayakar P., Raju K.V.B.,An experimental study on effect of cone diameters in penetration test on sandy soil, International Journal of Civil Engineering and Technology,V-8,I-8,PP-1581-1588,Y-2017.

6. Saritha B., Chockalingam M.P.,Photodradation of malachite green DYE using TIO2/activated carbon composite,International Journal of Civil Engineering and Technology,V-8,I-8,PP-156-163,Y-2017

7. Shendge R.B., Chockalingam M.P., Saritha B., Ambica A.,Swat modelling for sediment yield: A case study of Ujjani reservoir in Maharashtra, India,International Journal of Civil Engineering and Technology,V-9,I-1,PP-245-252,Y-2018

8. Chockalingam M.P., Balamurgan V.,Modernisation of an existing urban road-sector in Chennai, a case study report,International Journal of Civil Engineering and Technology,V-8,I-8,PP-1457-1467,Y-2017

9. Saritha B., Chockalingam M.P.,Adsorption study on removal of basic dye by modified coconut shell adsorbent, International Journal of Civil Engineering and Technology,V-8,I-8,PP-1370-1374,Y-2017

10. Saritha B., Chockalingam M.P.,Adsorptive removal of heavy metal chromium from aqueous medium using modified natural adsorbent,International Journal of Civil Engineering and Technology,V-8,I-8,PP-1382-1387,Y-2017

11. Chockalingam M.P., Palanivelraja S.,Retrospective analysis of a theoretical model used for forecasting future air quality near the north Chennai thermal power plant,International Journal of Civil Engineering and Technology,V-8,I-8,PP-1457-1467,Y-2017

12. Saritha B., Chockalingam M.P.,Photodegradation of methylene blue dye in aqueous medium by $\mathrm{Fe}-\mathrm{AC} / \mathrm{TiO} 2$ Composite,Nature Environment and Pollution Technology,V-17,I-4,PP-1259-1265,Y-2018

13. Shendge R.B., Chockalingam M.P., Kaviya B., Ambica A.,Estimates of potential evapotranspiration rates by three methods in upper Bhima Basin, In Maharashtra, India,International Journal of Civil Engineering and Technology,V-9,I-2,PP-475-480,Y-2018

14. Shendge R.B., Chockalingam M.P.,The soil and water assessment tool for Ujjani Reservoir,International Journal of Mechanical Engineering and Technology,V-9,I-2,PP-354-359,Y-2018

15. Shendge R.B., Chockalingam M.P.,A review on soil and water assessment tool,International Journal of Mechanical Engineering and Technology,V-9,I-2,PP-347-353,Y-2018

16. Sachithanandam P., Meikandaan T.P., Srividya T.,Steel framed multi storey residential building analysis and design,International Journal of Applied Engineering Research,V-9,I-22,PP-5527-5529,Y-2014

17. Meikandaan T.P., Ramachandra Murthy A.,Study of damaged RC beams repaired by bonding of CFRP laminates, International Journal of Civil Engineering and Technology,V-8,I-2,PP-470-486,Y-2017

18. Meikandaan T.P., Ramachandra Murthy A.,Retrofittng of reinforced concrete beams using GFRP overlays,International Journal of Civil Engineering and Technology,V-8,I-2,PP-423-439,Y-2017

19. Meikandaan T.P., Ramachandra Murthy A.,Flexural behaviour of RC beam wrapped with GFRP sheets,International Journal of Civil Engineering and Technology,V-8,I-2,PP-452-469,Y-2017

20. Meikandaan T.P., Murthy A.R.,Experimental study on strengthening of rc beams using glass Fiber,International Journal of Civil Engineering and 
Technology,V-9,I-11,PP-959-965,Y-2018

21. Meikandaan T.P., Hemapriya M.,Use of glass FRP sheets as external flexural reinforcement in RCC Beam,International Journal of Civil Engineering and Technology,V-8,I-8,PP-1485-1501,Y-2017

22. Saraswathy R., Saritha B.,Planning of integrated satellite township at Thirumazhisai,International Journal of Applied Engineering Research,V-9,I-22,PP-5558-5560,Y-2014

23. Saritha B., Ilayaraja K., Eqyaabal Z.,Geo textiles and geo synthetics for soil reinforcement,International Journal of Applied Engineering Research,V-9,I-22,PP-5533-5536,Y-2014

24. Ambica A., Saritha B., Changring G., Singh N B., Rajen M., Salman Md.,Analysis of groundwater quality in and around Tambaram taluk, Kancheepuram district,International Journal of Civil Engineering and Technology,V-8,I-8,PP-1362-1369,Y-2017

25. Arunya A., Sarayu K., Ramachandra Murthy A., Iyer N.R.,Enhancement of durability properties of bioconcrete incorporated with nano silica,International Journal of Civil Engineering and Technology,V-8,I-8,PP-1388-1394,Y-2017

26. Ilayaraja K., Krishnamurthy R.R., Jayaprakash M., Velmurugan P.M. Muthuraj S.,Characterization of the 26 December 2004 tsunami deposits in Andaman Islands (Bay of Bengal, India),Environmental Earth Sciences, V-66,I-8,PP-2459-2476,Y-2012

27. Ilayaraja K.,Morphometric parameters of micro watershed in Paravanar sub-basin, Cuddalore District,International Journal of Civil Engineering and Technology, V-8,I-8,PP-1444-1449,Y-2017

28. Ilayaraja K., Singh R.K., Rana N., Chauhan R., Sutradhar N.,Site suitability assessment for residential areas in south Chennai region using remote sensing and GIS techniques,International Journal of Civil Engineering and Technology,V-8,I-8,PP-1468-1475,Y-2017

29. Ilayaraja K., Reza W., Kumar V., Paul S., Chowdhary R.,Estimation of land surface temperature of Chennai metropolitan area using Landsat images,International Journal of Civil Engineering and Technology,V-8,I-8,PP-1450-1456,Y-2017

30. Chitra R.,Experimental study on beam using steel fiber and latex,International Journal of Civil Engineering and Technology,V-8,I-8,PP-1395-1403,Y-2017

31. Chitra R.,Analysis of traffic and management at Kovilambakkam intersection,International Journal of Civil Engineering and Technology,V-8,I-8,PP-1433-1443,Y-2017

32. Aswathy M.,Experimental study on light weight foamed concrete,International Journal of Civil Engineering and Technology,V-8,I-8,PP-1404-1412,Y-2017

33. Aswathy M.,Wastewater treatment using constructed wetland with water lettuce (Eichornia Crasipies),International Journal of Civil Engineering and Technology, V-8,I-8,PP-1413-1421,Y-2017

34. Kiruthiga K., Anandh K.S., Gunasekaran K, Assessment of influencing factors on improving effectiveness and productivity of construction engineers, 2015, International Journal of Applied Engineering Research, V - 10,I -17,p -13849-13854

\section{AUTHORS PROFILE}

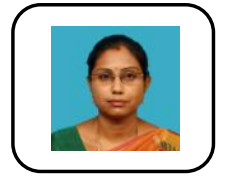

Dr.B.Saritha Associate Professor, Department of Civil Engineering, Bharath Institute of Higher Education and Research, Chennai, India

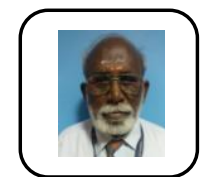

Dr.M.P.Chockalingam, Professor,, Department of Civil Engineering, Bharath Institute of Higher Education and Research, Chennai, India

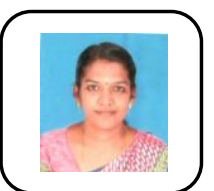

M.Aswathy, Assistant Professor, Department of Civil Engineering, Bharath Institute of Higher Education and Research, Chennai, India 